\title{
Global disparity in public awareness of the biological control potential of invertebrates
}

\author{
K.A.G. Wyckhuys a,b,c,d,*, G. Pozsgai a , G.L. Lovei ${ }^{\text {a,e }}$, L. Vasseur ${ }^{\text {a,f }}$, S.D. Wratten ${ }^{\text {a,g }}$, G.M. Gurr ${ }^{\text {a,h }}$, \\ O.L. Reynolds ${ }^{\mathrm{a}, \mathrm{h}, \mathrm{i}}$, M. Goettel ${ }^{\mathrm{a}, \mathrm{j}}$
}

a International Joint Research Laboratory on Ecological Pest Management, Fuzhou, China

b University of Queensland, Brisbane, Australia

c China Academy of Agricultural Sciences, Beijing, China

d Zhejiang University, Hangzhou, China

e Aarhus University, Slagelse, Denmark

${ }^{\mathrm{f}}$ Brock University, St. Catharines, Canada

g Lincoln University, Lincoln, New Zealand

${ }^{\text {h }}$ Graham Centre for Agricultural Innovation, Wagga Wagga, Australia

${ }^{i}$ New South Wales Department of Primary Industries, Menangle, Australia

j Lethbridge Research Centre, Agriculture E Agri-Food, Lethbridge, Canada

\section{H I G H L I G H T S}

- Invertebrates provide several key ecosystem services, yet are routinely disregarded

- Culturomics approaches reveal global visibility for 339 biological control organisms

- Major geographical and inter-taxa differences are recorded in public visibility

- Metrics reflect constituencies that are differentially attuned to biological control

- Our study guides awareness-raising, agricultural extension and policy dialogue

\section{A R T I C L E I N F O}

\section{Article history:}

Received 25 September 2018

Received in revised form 3 January 2019

Accepted 8 January 2019

Available online 9 January 2019

Editor: Deyi Hou

Keywords:

Agro-ecology

Ecological intensification

\section{GRAPHICALA B S T R A C T}

Global and country-specific disparities in the relationship between scientific salience and internet salience for $>300$ biological control invertebrates.

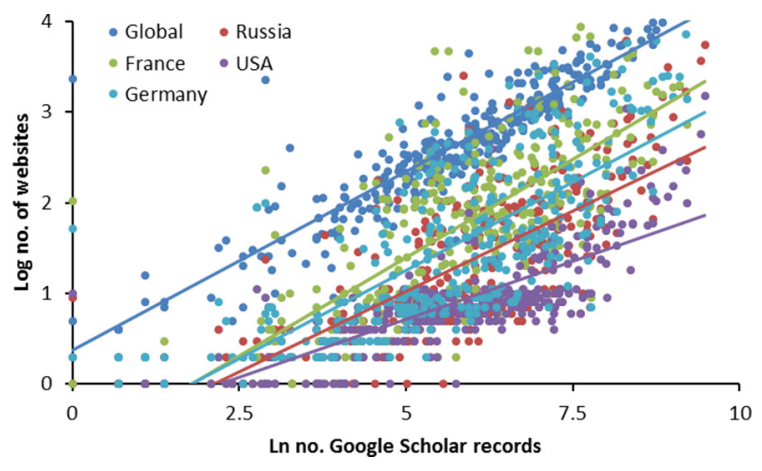

\begin{abstract}
A B S T R A C T
Invertebrates make up over 95\% of animal biodiversity on Earth and contribute to multiple ecosystem services (ES) in natural and human-dominated systems. One such service, biological control (BC) of herbivorous pests, is a core component of sustainable intensification of agriculture, yet its importance is routinely overlooked. Here we report a macro-scale, cross-cultural assessment of the public visibility (or 'salience') of BC invertebrates, using high-throughput analysis of large bodies of digitized text (i.e., 'culturomics'). Using binomial scientific name frequency as proxy for visibility, we compared the extent to which a given species featured in webpages within either scientific media or the entire worldwide web, and in total search volume at varying spatial scale. For a set of $339 \mathrm{BC}$ invertebrate species, scientific and internet coverage averaged 1020 and 1735 webpages, respectively. Substantial variability was recorded among BC taxa with Coleoptera, Hemiptera and Nematoda having comparatively high visibility. Online visibility exhibited large geographical variability ranging from France
\end{abstract}

\footnotetext{
* Corresponding author at: Institute of Plant Protection, Chinese Academy of Agricultural Sciences, No. 2 West Yuanmingyuan Rd., Haidian District, Beijing, 100193, China. E-mail address: kagwyckhuys@gmail.com (K.A.G. Wyckhuys).
} 
Functional biodiversity

Ecosystem services

Pest management

Computational science

Public perception

Big data covering BC invertebrates on average in 1050 webpages versus Thailand or Indonesia on just 31-38. This work represents the first extensive use of culturomics to assess public visibility of insect-mediated ES. As BC uptake is dictated by stakeholders' access to (agro-ecological) information, our work identifies geographicallydelineated areas that are differentially attuned to the concept of invertebrate $\mathrm{BC}$, pinpoints opportunities for focusing education campaigns and awareness-raising, enables real-time tracking of BC public appeal, and informs public policy.

(C) 2019 The Authors. Published by Elsevier B.V. This is an open access article under the CC BY-NC-ND license (http://creativecommons.org/licenses/by-nc-nd/4.0/)

\section{Introduction}

Biological control (BC), the suppression of vertebrate and invertebrate pests, weeds or plant pathogens by living organisms through competition, herbivory, parasitism or predation, features as an important ecosystem service (ES) worldwide. Conservatively valued at US $\$ 63 \mathrm{ha}^{-1} \mathrm{y}^{-1}$ across global biota, biological pest control is of critical importance to the sound functioning of terrestrial and aquatic ecosystems world-wide (Costanza et al., 2014). Estimated to be worth at least $\$ 4.5$ billion annually to US agriculture alone (Losey and Vaughan, 2006), insect-mediated biological control is progressively recognized as a core component of sustainable intensification schemes and regenerative farming tactics (Tscharntke et al., 2012; Bommarco et al., 2013; Garibaldi et al., 2017; LaCanne and Lundgren, 2018). As an environmentally-benign alternative to synthetic pesticides, BC supports a profitable production of healthy, nutritious agricultural produce from biologically-diverse farming systems.

Though BC has been used by growers for over 2000 years, with the oldest example being the manipulation of Oecophylla spp. weaver ants for pest control in Asian citrus orchards (Chen, 1962), its modern application dates back to the late 1800s (De Bach and Rosen, 1991). There are different types of BC approaches including importation BC (i.e., inoculative releases of carefully-selected exotic agents) and conservation $B C$ (i.e., promotion of native and naturalized agents). A third type of $\mathrm{BC}$ (i.e., augmentative biological control; $\mathrm{ABC}$ ) uses mass-production, shipment, and subsequent field release of biological control agents, and is implemented on approx. $10 \%$ of the world's agricultural land, primarily in protected cultivation but also in field crops such as corn, sugarcane, cotton and silviculture (van Lenteren and Bueno, 2003; Heimpel and Mills, 2017). ABC relies upon a comparatively high degree of involvement from various stakeholders, including farmers, government actors and private enterprises (Bale et al., 2008), and so is more likely to be known to sectors of the general public than other BC approaches that may be implemented by agencies and tend to require less farmer participation (Andrews et al., 1992).

At present, nearly 350 invertebrate natural enemy species are available for augmentative BC use in agriculture globally (van Lenteren, 2012; van Lenteren et al., 2018). Yet, despite the extensive availability of (and access to) such organisms, uptake of augmentative BC proceeds at a 'frustratingly' slow pace (van Lenteren, 2012). Multiple factors hamper the farm-level adoption and diffusion of these knowledge-intensive technologies, including its in-field success rate (Collier and Van Steenwyk, 2004; Sivinski, 2013). However, the absence of sufficient publicly-accessible information and farmers' lagging knowledge may be one of the main obstacles (Pretty and Bharucha, 2014; Reganold and Wachter, 2016; Wyckhuys et al., 2018). This is further compounded by a misconception and general indifference towards invertebrates among the broader public (Hogue, 1987; Kellert, 1993; Lemelin et al., 2016), a decline in the number of BC courses in core curricula at several academic institutions (Warner et al., 2011), and dwindling interest in this key ecosystem service across digitally-enabled groups of society such as 'generation Y' and 'millenials' (Brodeur et al., 2018).

To address these challenges, social science research can be deployed to conduct systematic broad-scale assessments of public perceptions and attitudes towards (beneficial) invertebrates, identify (farmer) knowledge gaps and help pinpoint associated opportunities for tailored extension or adult education (Wyckhuys and O'Neil, 2007). Yet, conventional social science approaches are increasingly constrained by declining survey response rates and lagging youth engagement (Sherren et al., 2017). On the other hand, considering how the internet currently permeates most levels of society, the digital humanities offer unparalleled opportunities to diagnose, map and track public interest in phenomena at a macro-scale (Galaz et al., 2010; McCallum and Bury, 2013; Proulx et al., 2014; Ladle et al., 2016). More specifically, the emerging field of 'culturomics' refers to the non-reactive, highthroughput collection, analysis and interpretation of large bodies of digitized text, or 'digital corpora' (Michel et al., 2011). These approaches have been embraced by scholars in disciplines ranging from political science, linguistics to conservation biology, yet are still to be used to assess public perceptions of agro-ecology or biological control.

Globally, over one billion websites exist, with >333 million domain names registered across the top-level domains (TLDs), and approx. 5 billion queries are submitted every day through Google search engines (Correia et al., 2017; Verisign, 2018). This expansive, ever growing corpus has been examined by various scholars, yielding novel insights into the determinants of public interest in climate change or specific ecosystem services (Anderegg and Goldsmith, 2014), and providing a powerful lens on human relations with the living world, including birds (Schuetz et al., 2015), fish (Stergiou, 2017) and butterflies (Żmihorski et al., 2013). In culturomics research, the (relative) number of websites that feature a particular species, or 'internet salience', is a reflection of its public visibility, or 'culturalness' (Correia et al., 2016). A species' scientific binomial name has been proposed as a robust metric to gauge its cultural visibility across linguistic, cultural or geographical boundaries (Correia et al., 2017). Public visibility can also be inferred by the number of search hits, as obtained through Google Trends, over a specific time frame (Schuetz et al., 2015; Do et al., 2015). Though cultural visibility can be considered as a 'species trait' on its own, it is equally shaped by a species' phenotypic (e.g., body size) or biogeographic (e.g., commonness) characteristics, and public attitudes or beliefs that revolve around that species (Żmihorski et al., 2013; Correia et al., 2016; Kim et al., 2014). If their nearabsence on postage stamps or under-representation on 'Noah's Ark' iconography is reflective of the low 'culturalness' of insects and invertebrates (Price, 1988; Nemesio et al., 2013), this could hamper their deliberate use, manipulation and conservation as ES-providing organisms in sustainable agriculture globally.

In this study, we embark upon a pioneering agro-ecology culturomics assessment and employ powerful text-mining tools to diagnose online public visibility of over 300 invertebrate biological control organisms. More specifically, we $i$ ) contrast the degree to which a particular organism features in the scientific literature with its internet salience; ii) compare the culturalness of organisms belonging to different taxa; and iii) assess the relative search volume of $\mathrm{BC}$ organisms with differing levels of internet salience. Aside from providing a first comprehensive overview of global cultural interest in invertebrate BC, our study points at opportunities for a tactical use of digital media analytics in the promotion of insect-mediated ecosystem services and in their effective incorporation into sustainable agricultural intensification worldwide (Pretty et al., 2018).

\section{Materials \& methods}

This analysis focused on the listing of 339 invertebrate natural enemy species that are used in augmentative biological control (ABC) 
of insect pests globally (van Lenteren, 2012; van Lenteren et al., 2018). These organisms covered eleven different groups: predatory mites (Acari; $n=51$ ), predaceous beetles (Coleoptera; $n=40$ ), true bugs (Hemiptera; $n=24$ ), insect-killing flies (Diptera; $n=11$ ), parasitic hymenopterans (Hymenoptera; $n=170$ ), entomphagous nematodes (Nematoda; $n=11$ ), lacewings (Neuroptera; $n=20$ ), predaceous thrips (Thysanoptera; $n=7$ ), praying mantids (Mantodea; $n=3$ ), centipedes (Chilopoda; $n=1$ ) and a predatory land snail (Mollusca; $n=1$ ).

To run the queries, we relied upon Google search engines as those currently represent $>73 \%$ of the share of the global search engine market (NetMarketShare, 2018). All queries were run between May 24 and June 15, 2018, from Hanoi, Vietnam, using a Lenovo laptop computer with regular internet connection and Google Chrome browser. Google Chrome represents $62.7 \%$ of the world's browser market (NetMarketShare, 2018). Using this set-up, we extracted data from the World Wide Web for each biological control species, at global and country-specific levels. All queries were run using binomial scientific names of a given species as quoted search strings (e.g., "Propylaea japonica"), thus restricting search returns to the exact match of the string. We exclusively conducted internet searches using scientific names (Correia et al., 2017), and did not correct for potential synonyms (Correia et al., 2018). For comparative purposes, we ran equivalent searches for species that might receive substantial public interest from aesthetic, human health or ES-delivery perspectives: the monarch butterfly Danaus plexippus (L.), the pollinators Apis mellifera L. and Bombus terrestris (L.), the virus-vectoring mosquitoes Culex pipiens L. and Aedes aegypti L., and the weaver ant Oecophylla smaragdina (Fabricius).

First, we used a Google Scholar (GS) interface to quantify the extent to which a given biological control organism features in the global scientific literature (Table 2). Despite considerable variability in the effectiveness of different search interfaces for library resources (Asher et al., 2013), Google Scholar does outperform commercially-available engines (Ciccone and Vickery, 2015). Using similar reasoning as in Correia et al. (2016), we employed the number of GS results as a direct measure of the extent to which a given species is covered in scientific documents and thus a proxy of its global scientific attention, or 'scientific salience' (Scis).

Second, we employed Google Custom Search to obtain organismspecific measures of 'internet salience', and to circumvent issues related to Google's personalization algorithms (Correia et al., 2016, 2017). A total of 11 different searches were carried out: one global search across all registered domains (as specified under editing mode at the Custom Search Engine platform), and a total of ten country-specific searches for Brazil, France, Germany, Indonesia, Kenya, Russia, Tanzania, Thailand, United Kingdom (UK) and the United States of America (USA) (populous countries with variable rates of internet usage, income distribution and economic growth; Table 1). The above set of countries was randomly chosen across four key geographical areas (i.e., Africa, Asia, Europe, Americas). Countries had wide-ranging ABC adoption rates, with European and North American nations (i.e., France, UK, Germany, USA) representing the world's largest ABC commercial market and other nations (e.g., Brazil) offering rapidly emerging market opportunities (van Lenteren et al., 2018). Country-level searches were delimited by the respective country web domains (i.e., .br, .fr, .de, .id, . $\mathrm{ke}, . \mathrm{ru}, \mathrm{tz}$, th, .uk, .us). Above searches were run exclusively using binomial scientific names, and no language preferences were set. The resulting output, the number of websites that feature a given biological control organism, was used as a proxy of its 'internet salience' (IS) over a particular geographic area. IS metrics were computed as absolute values (i.e., total number of websites), and as relative values (i.e., proportion of websites within a given country-code domain, ccTLD). For purposes of data visualization and to reveal the relative extent of internet visibility of a particular taxon, an additional 'public visibility index' was computed through (IS-SciS)/SciS (Table 2).

Third, we employed the 'Keywords Everywhere' interface (Anonymous, 2018) to quantify online search behavior as related to each of the different organisms. 'Keywords Everywhere' assesses search behavior of internet users, generating the total monthly searches that have been performed for a particular keyword over a 12-month time frame. The list of binomial scientific names was 'bulk-uploaded' as quoted search strings, and keyword metrics were generated for all websites (i.e., global extent) and those restricted to the UK and the USA (for which 'Keywords Everywhere' records are available). The above search volume thus constituted a quantitative metric of 'realtime public interest' for a specific biological control organism.

We conducted a linear regression analysis to relate organismspecific metrics of SciS and IS, either drawing upon the global dataset or country-specific records. Country-level analyses were also carried out accounting for local (commercial) availability of specific organisms, by excluding organisms that were locally not available (van Lenteren, 2012; van Lenteren et al., 2018). IS of individual biological control organisms either at the global or country-specific level was compared among taxa using a One-way Analysis of Variance (ANOVA), while a comparison of IS and SciS measures for a particular organism was done using a paired-samples $t$-test. Lastly, a linear regression analysis was conducted to relate organism-specific metrics of real-time public interest to IS measures for the global dataset and for the UK and USA based records (i.e., only countries from our list accessible through Keywords Everywhere). Where necessary and feasible, data were lognormal or rank-based inversed transformed to meet assumptions of normality and homoscedasticity, and all statistical analyses were conducted using SPSS (PASW Statistics 18).

Table 1

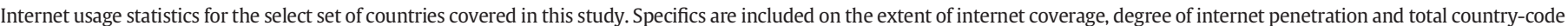

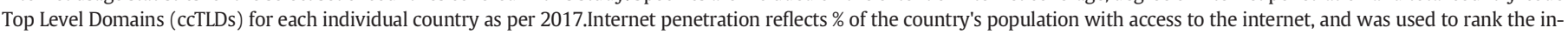
dividual countries.

\begin{tabular}{|c|c|c|c|c|c|}
\hline Country & $\begin{array}{l}\text { Gini index (2015 except where otherwise shown in } \\
\text { brackets) }\end{array}$ & $\begin{array}{l}\text { GDP }(\$ \\
\text { billion })\end{array}$ & $\begin{array}{l}\text { Total internet users (in } \\
\text { thousands) }\end{array}$ & $\begin{array}{l}\text { Internet penetration rate } \\
(\%)\end{array}$ & $\begin{array}{l}\text { Total no. of ccTLD* } \\
\text { (millions) }\end{array}$ \\
\hline United Kingdom & 33.2 & 2936.286 & 62,354 & 94.8 & 12.1 \\
\hline Germany & 31.7 & 4211.635 & 73,436 & 89.7 & 16.3 \\
\hline France & 32.7 & 2925.096 & 55,413 & 85.6 & 3.1 \\
\hline Russia & 37.7 & 1719.900 & 110,003 & 76.4 & 6.2 \\
\hline United States & 41.5 (2016) & $20,412.870$ & 245,436 & 76.2 & 1.7 \\
\hline Brazil & 51.3 & 2138.918 & 123,927 & 59.7 & 3.9 \\
\hline Thailand & 36 & 483.739 & 32,710 & 47.5 & 0.068 \\
\hline Indonesia & 39.5 (2013) & 1074.966 & 66,244 & 25.4 & 0.256 \\
\hline Kenya & 40.8 & 88.271 & 12,600 & 26.0 & 0.058 \\
\hline Tanzania & $37.8(2011)$ & 56.664 & 7224 & 13.0 & 0.015 \\
\hline
\end{tabular}

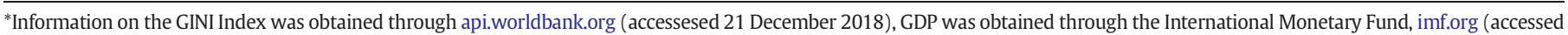

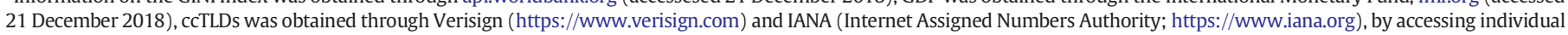
country URLs. 
Table 2

Overview of the different metrics used in this study.

\begin{tabular}{|c|c|c|c|c|}
\hline Metric & Description & Search engine & Spatial coverage & Formula \\
\hline $\begin{array}{l}\text { Scientific salience } \\
\text { (SciS) }\end{array}$ & Number of scientific documents that feature a particular organism & Google scholar & Global & - \\
\hline Internet salience (IS) & $\begin{array}{c}\text { Number of websites that feature a particular organism, indicative of its cultural visibility } \\
\text { and/or interest }\end{array}$ & $\begin{array}{l}\text { Google custom } \\
\text { search }\end{array}$ & $\begin{array}{l}\text { Global, } \\
\text { country-specific }\end{array}$ & - \\
\hline Public visibility index & Extent of public visibility or 'culturalness' relative to SciS of a particular organism & 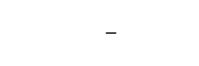 & $\begin{array}{c}\text { Global, } \\
\text { country-specific }\end{array}$ & $(I S-S c i S) / S c i S$ \\
\hline $\begin{array}{l}\text { Real-time public } \\
\text { interest }\end{array}$ & $\begin{array}{c}\text { Monthly search volume averaged over a } 12 \text {-month time frame, reflective of online search } \\
\text { behavior }\end{array}$ & $\begin{array}{l}\text { Keywords } \\
\text { everywhere }\end{array}$ & $\begin{array}{l}\text { Global, } \\
\text { country-specific }\end{array}$ & - \\
\hline
\end{tabular}

\section{Results}

i. Scientific and internet salience

Web searches yielded 385 (135; 1095) (median; Q1, Q3) scientific documents and $483(168 ; 1415)$ public webpages per BC organism. For any given organism, the number of public webpages was consistently and significantly higher than its respective number of scientific records (Paired samples Student's $t$-test, $t=-8.390, \mathrm{df}=338, p<$ $0.001)$.

In terms of SciS, the five most featured organisms were Coccinella septempunctata Linnaeus (Coleoptera: Coccinellidae; 13,100 documents), Harmonia axyridis Pallas (Coleoptera: Coccinellidae; 12,300), Nasonia vitripennis (Walker) (Hymenoptera: Pteromalidae, 10,000), Chrysoperla carnea Stephens (Neuroptera: Chrysopidae; 9950) and Phytoseiulus persimilis Evans (Acari: Phytoseiidae; 8990). The highest SciS for Diptera, Hemiptera, Mantodea and Nematoda were Episyrphus balteatus De Geer (4090), Orius insidiosus (Say) (5030), Mantis religiosa (Linnaeus) (4050) and Steinernema carpocapsae (Weiser) (8150), respectively. This compared to SciS metrics for the mosquitoes A. aegypti $(212,000)$ and $C$. pipiens $(45,100)$ and the honeybee $A$. mellifera (201,000). Overall, 95\% of BC organisms had SciS below 4100 documents and $75 \%$ of them had $<1000$ records per organism; $20.1 \%$ of BC organisms featured on $<100$ scientific documents globally.

As for IS, the five most featured organisms were the praying mantis M. religiosa (83,200), C. septempunctata $(33,600)$, H. axyridis $(29,300)$, $P$. persimilis $(15,400)$ and $C$. carnea $(15,300)$. The highest IS measures for Diptera, Hemiptera, Hymenoptera and Nematoda were E. balteatus $(11,700), 0$. insidiosus $(6200), N$. vitripennis $(10,700)$ and S. carpocapsae $(10,500)$. The above compared to IS metrics of e.g., 961,000 for A. aegypti, 231,000 for $A$. mellifera, or 70,100 for D. plexippus. Overall, $95 \%$ of BC organisms had IS $<6000$ webpages and $80 \%>2000$ per organism; $17.6 \%$ of them featured on $<100$ webpages globally.

ii. Global and country-level relationship between scientific salience? and internet salience

At a global level, a significant positive regression was recorded between organism-specific SciS and IS measures $\left(\mathrm{F}_{1,334}=2257.0, p<\right.$ $0.001 ; R^{2}=0.871$ ) (Fig. 1). This same pattern was also confirmed for individual countries: Russia $\left(F_{1,334}=524.0, p<0.001 ; R^{2}=0.611\right)$, France $\left(\mathrm{F}_{1,334}=469.9, p<0.001 ; \mathrm{R}^{2}=0.585\right)$, USA $\left(\mathrm{F}_{1,335}=722.6, p<0.001\right.$; $\left.\mathrm{R}^{2}=0.683\right)$, Germany $\left(\mathrm{F}_{1,334}=553.9, p<0.001 ; \mathrm{R}^{2}=0.624\right)$, Brazil $\left(\mathrm{F}_{1,334}=751.6, p<0.001 ; \mathrm{R} 2=0.692\right)$, Indonesia $\left(\mathrm{F}_{1,334}=422.3, p<\right.$ $\left.0.001 ; \mathrm{R}^{2}=0.558\right)$, Thailand $\left(\mathrm{F}_{1,334}=253.0, p<0.001 ; \mathrm{R}^{2}=0.431\right)$, and Kenya $\left(F_{1,334}=284.3, p<0.001 ; R^{2}=0.460\right)$. Overall, the positive regression patterns were sustained when correcting for local (commercial) availability of individual organisms (based on continent-level records in 13, 14). More specifically, the following positive regressions were recorded: Russia $\left(F_{1,233}=415.3, p<0.001 ; R^{2}=0.641\right)$, France $\left(\mathrm{F}_{1,204}=319.1, \mathrm{p}<0.001 ; \mathrm{R}^{2}=0.610\right), \mathrm{USA}\left(\mathrm{F}_{1,94}=338.4, \mathrm{p}<0.001\right.$; $\left.\mathrm{R}^{2}=0.783\right)$, Germany $\left(\mathrm{F}_{1,204}=359.5, \mathrm{p}<0.001 ; \mathrm{R}^{2}=0.638\right)$, Brazil
$\left(\mathrm{F}_{1,67}=108.1, \mathrm{p}<0.001 ; \mathrm{R}^{2}=0.617\right)$, Indonesia $\left(\mathrm{F}_{1,50}=62.084, \mathrm{p}<\right.$ $\left.0.001 ; \mathrm{R}^{2}=0.5584\right)$, Thailand $\left(\mathrm{F}_{1,51}=24.397, \mathrm{p}<0.001 ; \mathrm{R}^{2}=0.324\right)$, and Kenya $\left(\mathrm{F}_{1,29}=12.9, p=0.001 ; \mathrm{R}^{2}=0.309\right)$.

Not all organisms featured to equal extent on webpages in the different countries, with $99 \%$ of the 339 BC organisms being covered in Germany and the UK, 95\% coverage in Brazil, 64\% in Thailand and 38\% in Kenya. Considerable between-country variability was recorded in the extent to which BC species feature online, with a mean of 1050 $(S D=5100)$ webpages per species in France versus $167(S D=596)$, $31(\mathrm{SD}=120), 38(\mathrm{SD}=120)$ and $65(\mathrm{SD}=469)$ for Russia, USA, Indonesia and Kenya, respectively. In Tanzania, only 11 species featured on local sites with $1 \pm 1$ webpage per organism. France had significantly higher IS measures for biological control species than e.g., USA or Russia, in both absolute (Paired samples Student's $t$-test, $t=22.132$, df $=299$, $p<0.001 ; t=14.524, \mathrm{df}=308, p<0.001$, respectively) as relative numbers $(t=16.262, \mathrm{df}=299, p<0.001 ; t=-23.236$, df $=308, p<0.001$, respectively). As compared with France, IS of individual BC organisms in e.g., Brazil was $9.14 \pm 27.65$ times lower (Fig. 1A, B). In certain countries such as Kenya, a mere $38.6 \%$ of BC invertebrates featured on webpages in the country domain.

Significant regressions were equally obtained between organismspecific SciS and IS metrics, when assessing global patterns for each of the most representative taxa (see Table 3 ).

iii. Taxa-specific differences in internet salience

Organism-specific IS and SciS measures varied among the seven most representative natural enemy taxa (Table 3), with Nematoda attaining both the highest levels of scientific and internet salience. Out of the 11 nematode species that are used globally, seven had SciS $>1000$ per organism and three species (i.e., Steinernema feltiae Filipjev, Heterorhabitis bacteriophora Poinar, and S. carpocapsae) attained SciS $>$ 5000. Hemiptera had comparatively high SciS and IS, whilst Coleoptera and Diptera equally received high levels of internet salience (though Diptera featured to lesser extent in scientific media).

On the country level, significant inter-taxa differences were recorded for IS of the six most representative taxa (Fig. 3) for Russia $\left(F_{5,310}=\right.$ $7.322, p<0.001)$, Germany $\left(F_{5,309}=3.466, p=0.005\right)$ and Indonesia $\left(\mathrm{F}_{5,309}=2.585, p=0.026\right)$. In France, $20 \%$ of Coleoptera featured on $>1000$ webpages, with coccinellids such as $H$. axyridis $(58,200)$, C. septempunctata (40,300), Adalia bipunctata L. (31,900), Hippodamia variegata (Goeze) (8810) and Exochomus quadripustulatus L. (4810) most mentioned. When correcting for local (commercial) availability of BC organisms, significant inter-taxa IS differences were evident for Russia $\left(\mathrm{F}_{5,187}=8.735, p<0.001\right)$, France $\left(\mathrm{F}_{5,186}=3.157, p=0.009\right)$ and Germany $\left(\mathrm{F}_{5,186}=4.479, p=0.001\right)$, while no statistically-significant inter-taxa IS differences were recorded for the other countries.

iv. Relationship between internet salience and real-time public interest

When assessing real-time public interest (as monthly 'hits' through 'Keywords Everywhere') in BC organisms, only 41.0\%, 39.8\% and 40.7\% 
A

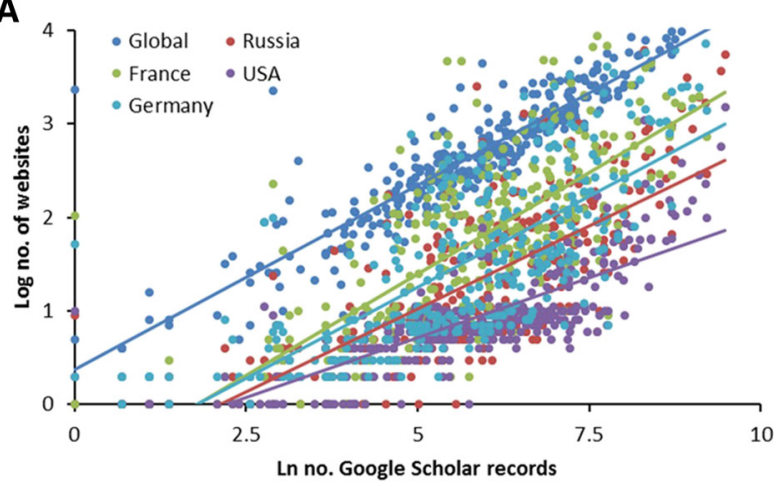

C

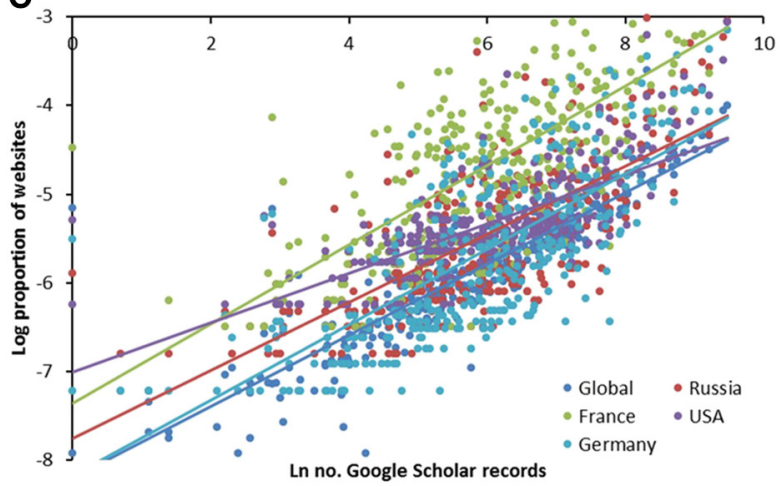

B

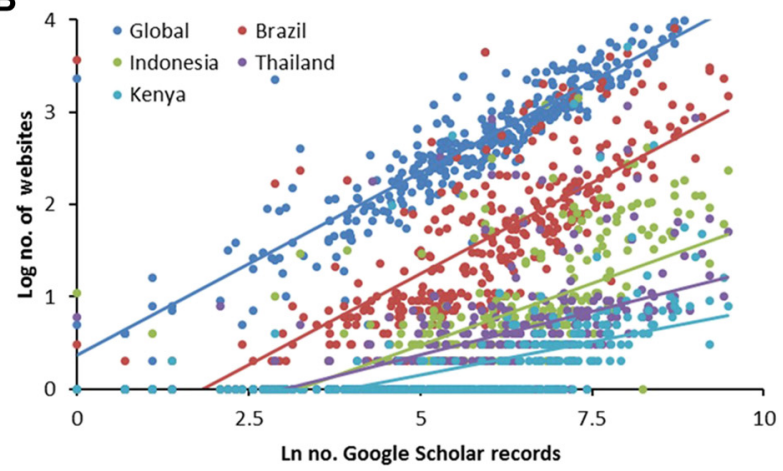

D

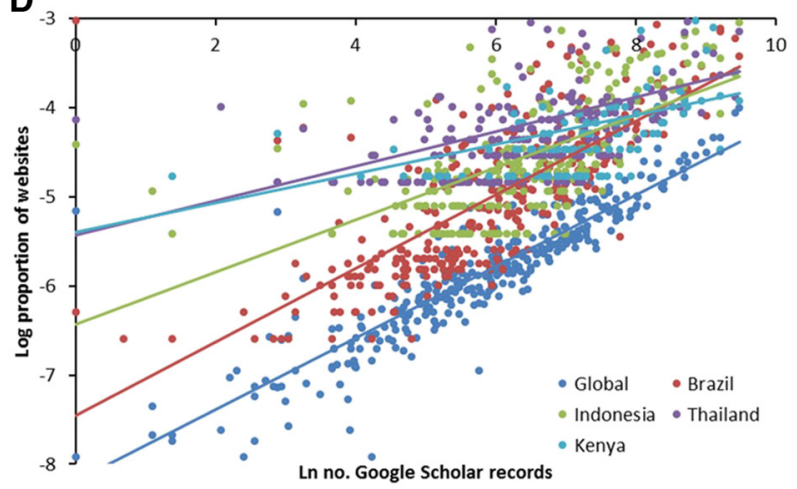

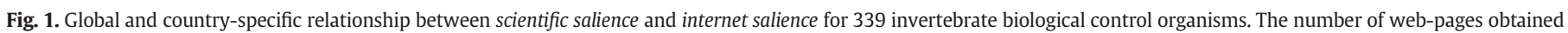

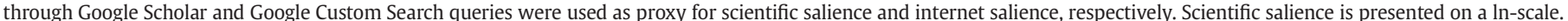

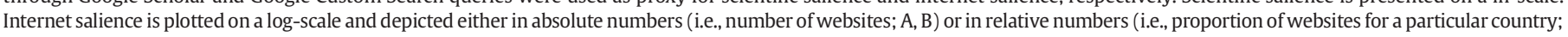

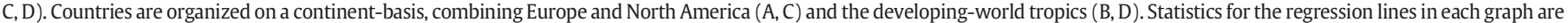
described in the text.

of all species featured in searches at global, UK- and USA-specific levels. At these respective levels, BC organisms received an average of $926.5 \pm$ 5297.7 (mean \pm SD), $35.6 \pm 142.8$ and $121.2 \pm 525.6$ searches per month, respectively. Global search interest differed substantially among taxa, with search volume covering 20.0\% (Neuroptera), 33.3\% (Acari), 45.0\% (Diptera), 45.4\% (Coleoptera), and 90.9\% Nematoda species.

The five species that received most monthly searches globally during the preceding year (i.e., 2017-2018) were M. religiosa (60,500), H. axyridis $(14,800), C$. septempunctata (8100), P. persimilis (2900) and C. carnea (2400). In the UK, monthly search volume was the highest for $H$. axyridis (1600), with C. septempunctata (390), M. religiosa (210), P. persimilis (170) and the whitefly parasitoid Encarsia formosa Gahan (140) following in ranked order. In the USA, a similar ranking for the five most popular organisms was obtained, with search volume ranging between 480 and 5400, $\mathrm{H}$. axyridis the most commonly searched organism, and Hippodamia convergens (Guërin-Mëneville) featuring instead of $C$. carnea.

For biological control organisms that featured in online searches, real-time public interest was significantly related to internet salience at a global, UK- and USA- specific level $\left(\mathrm{F}_{1,136}=538.732, p<0.001, \mathrm{R}^{2}\right.$ $=0.798 ; F_{1,131}=102.581, p<0.001, R^{2}=0.439 ; F_{1,133}=121.595, R^{2}$ $=0.478$, respectively) (Fig.4).

\section{Discussion}

Combining powerful text-mining tools and culturomics approaches to assess the visibility of biological control invertebrates, we reveal how these organisms feature on average on 1735 webpages globally, as compared to $34,700-231,000$ for domesticated bee pollinators or 50,900-961,000 for prominent ecosystem-disservice providers

Table 3

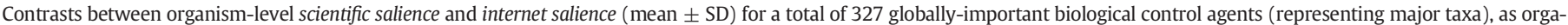

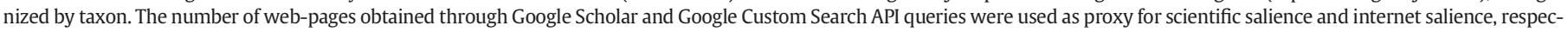

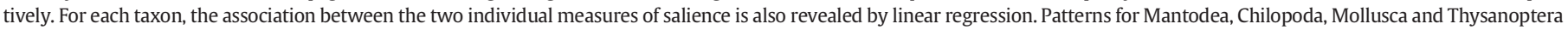
are not shown due to paucity of data.

\begin{tabular}{|c|c|c|c|c|c|c|}
\hline Classification & $\mathrm{n}$ & Scientific salience & Internet salience & Regression parameters & F statistic & $\mathrm{R}^{2}$ \\
\hline Acari & 51 & $875.9 \pm 1533.9 a$ & $1167.4 \pm 2398.0 \mathrm{a}$ & $y=-0.007+0.938 x$ & $F_{1,49}=291.083, P<0.001$ & 0.856 \\
\hline Coleoptera & 40 & $1544.4 \pm 3013.9 \mathrm{a}$ & $3089.2 \pm 7120.9 a b$ & $\mathrm{y}=0.035+0.977 \times$ & $\mathrm{F}_{1,37}=399.685, \mathrm{P}<0.001$ & 0.915 \\
\hline Diptera & 11 & $798.0 \pm 1271.7 \mathrm{a}$ & $2112.2 \pm 3602.6 a b$ & $\mathrm{y}=-0.024+1.171 \times$ & $\mathrm{F}_{1,9}=55.224, \mathrm{P}<0.001$ & 0.860 \\
\hline Hemiptera & 24 & $1339.8 \pm 1262.2 \mathrm{ab}$ & $1951.8 \pm 1741.2 \mathrm{ab}$ & $\mathrm{y}=0.010+0.987 x$ & $\mathrm{~F}_{1,22}=135.686, \mathrm{P}<0.001$ & 0.860 \\
\hline Hymenoptera & 170 & $844.5 \pm 1333.5 \mathrm{a}$ & $1048.3 \pm 1680.8 \mathrm{a}$ & $y=0.048+0.888 x$ & $\mathrm{~F}_{1,168}=1742.721, \mathrm{P}<0.001$ & 0.912 \\
\hline Nematoda & 11 & $2701.2 \pm 2731.1 b$ & $3550.7 \pm 3814.4 b$ & $y=0.054+0.897 x$ & $\mathrm{~F}_{1,9}=112.510, \mathrm{P}<0.001$ & 0.926 \\
\hline Neuroptera & 20 & $876.5 \pm 2225.1 \mathrm{a}$ & $1258.7 \pm 3392.6 a$ & $y=0.021+0.947 x$ & $\mathrm{~F}_{1,18}=209.291, \mathrm{P}<0.001$ & 0.921 \\
\hline Statistics & & $\mathrm{F}_{6,319}=3.774, \mathrm{P}=0.001$ & $\mathrm{~F}_{6,320}=4.052, P=0.001$ & & & \\
\hline
\end{tabular}


(i.e., disease-carrying mosquitos). Coleoptera, Hemiptera and Nematoda demonstrated comparatively high public and scientific visibility. In contrast, Acari, Hymenoptera and Neuroptera were less apparent. Significant differences were also apparent among geographical domains. Further, real-time public interest varied greatly between individual taxa and countries, with charismatic ladybeetles and praying mantids dominating most public attention.

Internet salience (IS) of biological control species (entered as binomial scientific names) in our study is similar to that of birds in the IUCN Red List of Threatened Species (i.e., $1624 \pm 48$ webpages per organism; Correia et al., 2017), yet the variability in IS among invertebrates is substantially higher. Furthermore, our measures vary greatly from those obtained when entering vernacular names, i.e., 10,873 \pm 4372 for red-listed birds (Correia et al., 2017), 643-1872 for English popular names of Brazilian birds (Correia et al., 2016), 5180-6.1 million for 180 popular Polish birds or $6850-436$ million for 52 common UK butterflies (Żmihorski et al., 2013). Such disparity is further accentuated by contrasting global internet salience of the monarch butterfly D. plexippus as scientific name (i.e., 70,100 ) versus popular name (i.e., 1.75 million) (see Fig. 2). Though our assessment is supported by Correia et al. (2017), who validated the use of scientific name frequency as a reliable indicator of public interest in nature, we recognize that most invertebrates do not possess vernacular names. In the meantime, we do expect an important underrepresentation of IS for charismatic and well-known invertebrates (i.e., ladybirds, lacewings and hoverflies), such as the marmalade hoverfly E. balteatus or the sevenspotted ladybird C. septempunctata.

Indeed, with IS below 643, a total of 194 (out of 339) biological control invertebrates receive comparable or lower global public interest than Brazilian hummingbirds, thus mirroring findings of Nemesio et al. (2013). Moreover, for $18 \%$ species, information can be obtained on $<100$ webpages worldwide. This is in stark contrast with pollinators such as B. terrestris or A. mellifera (IS 34,700 and 231,000, respectively) or disease-carrying mosquitos, i.e., C. pipiens or A. aegypti (IS 50,900 and 961,000 , respectively). Species with medical or human health importance thus receive vastly higher public visibility than those relevant to agriculture, or with important conservation value. A number of phenotypic and biogeographic traits, such as body size, aesthetic appeal (i.e., colorfulness) and commonness are likely determinants of species salience (Schuetz et al., 2015; Correia et al., 2016; Kim et al., 2014; Sitas et al., 2009; Żmihorski et al., 2013), and may explain the

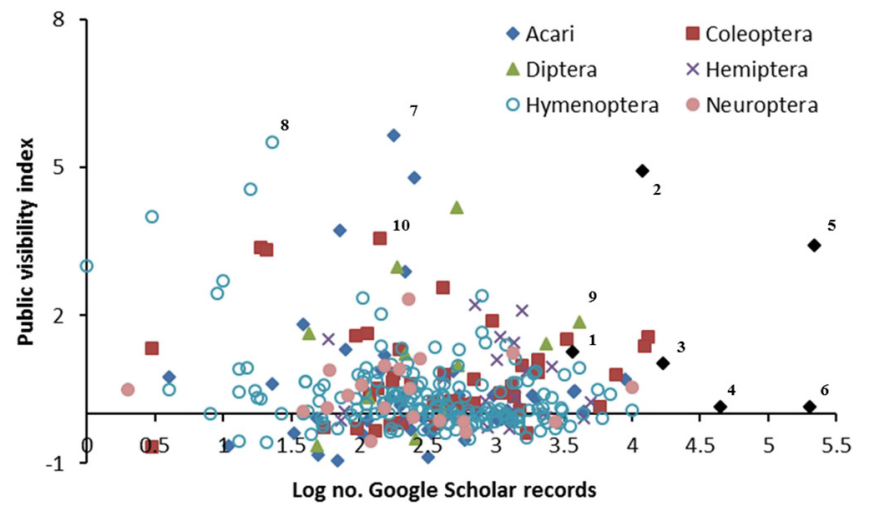

Fig. 2. Organism-specific relationship between scientific salience (i.e., number of GS records; log-transformed) and a public visibility index for 306 biological control organisms belonging to six key taxa. The latter metric is computed through (IS-SciS)/SciS. For ease of presentation, one organism with high relative visibility was omitted from the graph, i.e., Ampulex compressa (Hymenoptera) at relative visibility $=10.81$. The following key ecosystem service and disservice provider organisms are shown in the graph as black diamonds: 1. Oecophylla smaragdina; 2. Danaus plexippus; 3. Bombus terestris; 4. Culex pipiens; 5. Aedes aegyptii; 6. Apis mellifera; 7. Macrocheles robustulus; 8. Leptomastix algirica; 9. Episyrphus balteatus; 10 . Dalotia coriaria. An interactive version of this graph can be found online at http://ec2-13-55-55-51.ap-southeast-2.compute.amazonaws.com:3838/ Culturomics/.
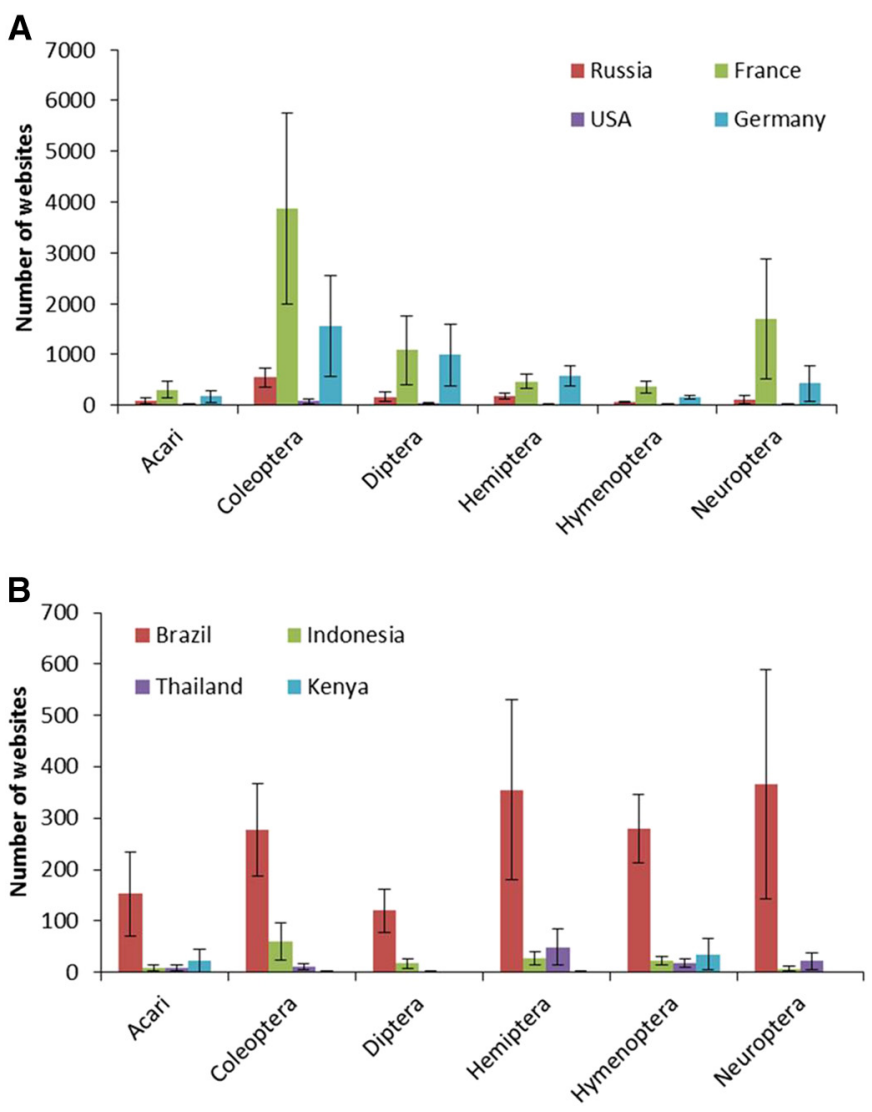

Fig. 3. Comparative internet salience (mean $\pm \mathrm{SE}$ ) of biological control organisms within six different taxa, as depicted on a country basis. Internet salience is computed for each individual organism based upon the number of web-pages obtained through Google Custom Search queries, and then averaged per taxon. Accompanying statistics are outlined in the text.

comparatively low IS for mites obtained in this study. Salience for certain groups, e.g. Coleoptera or Mantodea, are shaped by few colorful species of ladybeetles, species that excite curiosity (e.g., the "bodysnatcher' Ampulex compressa (Fabr.) IS 4490 vs. SciS 380; Fig. 2) or the praying mantis, Mantis religiosa. Other organisms, e.g., the rove beetle Dalotia coriaria (Kraatz) (Fig. 2), feature on Wikipedia or are regularly used as laboratory model organisms. Yet, for large-bodied parasitic

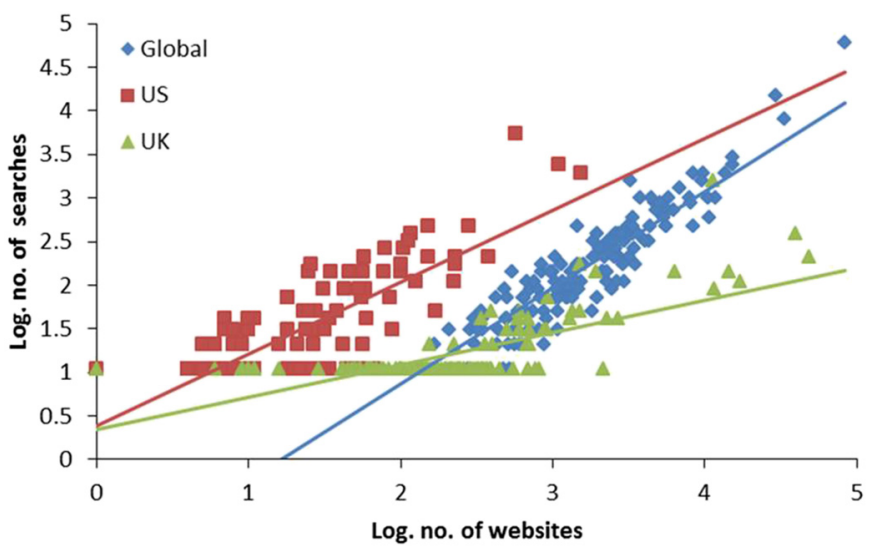

Fig. 4. Relationship between the real-time public interest and internet salience (logtransformed) of 339 biological control organisms, based upon the extent those feature on either global or country-level websites. Real-time public interest is reflected by the monthly search volume for individual binomial scientific names (log-transformed), as computed through Keywords Everywhere either for a global search or for US- and UKrestricted queries. Regression statistics are represented in the text. 
hymenopterans, their complex and obscure lifestyle (e.g., as endoparasitoids) can preclude broad public appreciation (e.g., Wyckhuys and O'Neil, 2007). Some of the above 'super-salient' species, i.e. those that attain comparatively high levels of cultural visibility (Correia et al., 2017), can possibly be used as entry-points to frame broader issues of food safety, agricultural sustainability or wild-life friendly farming, and help bolster public understanding of biological control invertebrates (Ladle et al., 2016).

On the other hand, the world's biological control producers should be commended for adopting innovative marketing strategies to position some of the commercially-available agents. With product names such as Dyna-mite, Macro-mite, ABS-System, Spidex or Ulti-mite, biological control producers have lifted the public profile of small-bodied Acari and secured a place for the minute $P$. persimilis among the world's five best featured invertebrate natural enemies. Such tailored marketing may equally explain elevated IS for Nematoda, organisms that are broadly commercialized and require detailed application guidelines for in-field usage. Notwithstanding its relatively high search volume (i.e., 2900 hits per month globally), the value of $P$. persimilis as a 'biological control emblem' (see Ladle et al., 2016) may be constrained by its small size and therefore may only find a soundboard among growers that are familiar with its use. Other larger-bodied organisms such as ladybeetles, praying mantids, pirate bugs (e.g., O. insidiosus) or Oecophylla spp. weaver ants likely feature far more prominently in (historical) cultural narratives, evoke wonder or curiosity, and thus can help muster popular support, funding or (possibly) farm-level adoption (Wyckhuys et al., 2018).

A careful (cross-cultural) analysis of organisms that evoke public interest, as enabled through culturomics, is particularly important given the overall negative public attitude towards invertebrates in general and specifically against insects. At a global level, insects -except for honeybees and a small set of aesthetically-appealing species- are regularly viewed with attitudes ranging from indifference, avoidance to outright fear (Kellert, 1993; Baldwin et al., 2008). In a survey of USA college students, overall knowledge of insects was limited to as little as 13 species, with organisms regularly dichotomized as either beautiful or bothersome (Shipley and Bixler, 2017), notwithstanding children's extensive knowledge of 'artificial' Pokemon creatures (Balmford et al., 2002). Similar attitudes exist in Switzerland and Japan (Breuer et al., 2015; Hosaka et al., 2017), while in Arizona (USA) only 6\% of 1117 households voiced pleasure upon encountering invertebrates outside their home. Human perceptions towards insects are molded by childhood encounters, species traits (i.e., aesthetic appeal) (Lemelin et al., 2016), and insects' cultural importance (Wyckhuys et al., 2018), thus imposing considerable bias towards colorful butterflies or (domesticated) pollinators. Though the growing public appreciation of honeybee pollinators is evidently to be applauded (Schönfelder and Bogner, 2017), biological control organisms provide equally valuable and economically-important services (Southwick and Southwick Jr., 1992) and this attracts little public recognition.

Another way in which culturomics can help advance agro-ecology or insect biological control is by capturing (geographically-delineated) constituencies that are attuned to invertebrates (and their associated ESs), or where public perception towards e.g., biological control is less positive (Ladle et al., 2016). This is accentuated by a stark disparity in internet salience at the country-level (Fig. 1), partially due to restricted (commercial) availability of natural enemies in tropical Africa or South America (Schuetz et al., 2015). Yet, we note equally pronounced intercountry differences among western nations with similar degree of agricultural development, literacy and adult education, or internet connectivity (e.g., France and Germany vs. USA). Given the multi-billion dollar benefits of biological control to USA agriculture and the key role natural enemies assume in agro-production systems across North America (Losey and Vaughan, 2006; Naranjo et al., 2015), it is surprising to note their low visibility on national websites. One key confounding factor though is the fact that USA-related sites do not regularly rely upon the country domain (i.e., .us) but instead on general domains such as . com, .org, .net and others. In the meantime, many of the latter sites are also widely consulted outside of the USA.

Particularly for knowledge-intensive technologies such as invertebrate biological control, availability of and access to (locally-relevant, digestible) information is essential (Wyckhuys et al., 2018). For multiple countries in the global south (e.g., Kenya, Thailand, Indonesia), the overall low IS of BC organisms could hamper diffusion of biological control, unless local extension programs are paper-based. Also, the low "culturalness; of biological control in these countries is likely magnified by an under-representation of key beneficiaries (i.e., farmers, farm workers) on the internet - which could be captured to certain degree by a country's internet connectivity or Gini indices (Graham et al., 2015). For instance, the mere visibility of $11 / 339$ organisms in Tanzania can affect the establishment and uptake of sustainable intensification, or the nation's organic (cotton, coffee, cacao) farming sector and its nearly 150,000 producers (Willer and Lernoud, 2016). Hence, our country-level mapping of visibility of BC invertebrates has immediate implications for policy (Reganold and Wachter, 2016), development of tailored education and farmer extension programs, effective deployment of incentive schemes (Naranjo et al., 2015) and the successful promotion of biological control as core component of sustainable food systems (Waterfield and Zilberman, 2012).

Agricultural development should not be a one-way process. Evidence now abounds of how intensified farming can undermine onfarm biodiversity and linked ESs, and how global food systems are founded on a fast-decaying basis (LaCanne and Lundgren, 2018; Bianchi et al., 2006; Holland et al., 2014; Lundgren and Fausti, 2015; Hallmann et al., 2017; Tomasetto et al., 2017). As a core component of agro-ecology, insect biological control -a millennia-old tactic and invaluable ES- can help regenerate the world's farming systems. As access to information facilitates farm-level uptake and diffusion of biological control, our study pinpoints immediate opportunities for remediative education campaigns, awareness-raising efforts or farmer extension programs. In addition to opening a new (digital) chapter of cultural entomology, our culturomics approach permits real-time tracking of the public appeal of insect-mediated ecosystem services, helps identify invertebrate organisms that could act as 'agro-ecology' emblems or flagships, and guides public policy. In the 2018 report of Intergovernmental Science-Policy Platform on Biodiversity \& Ecosystem Services (IPBES) (Scholes et al., 2018), emphasis was placed on incorporating (invertebrate) biodiversity in policy-making, recognizing peoples' capabilities to derive benefits from nature (Sangha et al., 2018), and realizing the central role of culture in examining links between people and nature (Díaz et al., 2018). Our work covers all three of these themes, provides an unprecedented global perspective on the 'culturalness' of ecosystem-providing invertebrates, and helps advance their effective incorporation in decision-making at a global scale.

\section{Acknowledgments}

We are grateful to Fujian Agriculture and Forestry University (Fuzhou, China) and its ' 111 ' program, for facilitating regular meetings amongst team members and for creating the necessary space for research planning and coordination. This research did not receive any specific grant from funding agencies in the public, commercial, or not-forprofit sectors.

\section{References}

Anderegg, W.R., Goldsmith, G.R., 2014. Public interest in climate change over the past decade and the effects of the 'climategate' media event. Environ. Res. Lett. 9, 054005

Andrews, K.L., Bentley, J.W., Cave, R.D., 1992. Enhancing biological control's contributions to integrated pest management through appropriate levels of farmer participation. Fla. Entomol. 75, 429-439.

Anonymous, 2018. https://keywordseverywhere.com/, Accessed date: 18 July 2018.

Asher, A.D., Duke, L.M., Wilson, S., 2013. Paths of discovery: comparing the search effectiveness of EBSCO discovery service, summon, google scholar, and conventional library resources. Coll. Res. Libr. 74, 464-488. 
Baldwin, R.W., et al., 2008. Public perceptions of pest problems. Am. Entomol. 54, 73-79. Bale, J.S., Van Lenteren, J.C., Bigler, F., 2008. Biological control and sustainable food production. Philos. T. Roy. Soc. B 363, 761-776.

Balmford, A., et al., 2002. Why conservationists should heed Pokémon. Science 295, 2367.

Bianchi, F.J., Booij, C.J.H., Tscharntke, T., 2006. Sustainable pest regulation in agricultural landscapes: a review on landscape composition, biodiversity and natural pest control. P. Roy. Soc. Lond. B Bio. 273, 1715-1727.

Bommarco, R., Kleijn, D., Potts, S.G., 2013. Ecological intensification: harnessing ecosystem services for food security. Trends Ecol. Evol. 28, 230-238.

Breuer, G.B., et al., 2015. The importance of being colorful and able to fly: interpretation and implications of children's statements on selected insects and other invertebrates. Int. J. Sci. Educ. 37, 2664-2687.

Brodeur, J., et al., 2018. Trends in biological control: public interest, international networking and research direction. BioControl 63, 11-26.

Chen, S., 1962. The oldest practice of biological control: the culture and efficacy of Oecophylla smaragdina Fabr. in orange orchards. Acta Entomol. Dermatol. Sin. 11, 401-407.

Ciccone, K., Vickery, J., 2015. Summon, EBSCO Discovery Service, and Google Scholar: A comparison of search performance using user queries. Evid. Based Libr. Inf. Pract. $10,34-49$.

Collier, T., Van Steenwyk, R., 2004. A critical evaluation of augmentative biological control. Biol. Control 31, 245-256.

Correia, R.A., et al., 2016. Familiarity breeds content: assessing bird species popularity with culturomics. PeerJ 4, e1728.

Correia, R.A., et al., 2017. Internet scientific name frequency as an indicator of cultural salience of biodiversity. Ecol. Indic. 78, 549-555.

Correia, R.A., et al., 2018. Nomenclature instability in species culturomic assessments: why synonyms matter. Ecol. Indic. 90, 74-78.

Costanza, R., et al., 2014. Changes in the global value of ecosystem services. Glob. Environ. Chang. 26, 152-158.

De Bach, P., Rosen, D., 1991. Biological Control by Natural Enemies. Cambridge University Press, Cambridge.

Díaz, S., et al., 2018. Assessing nature's contributions to people. Science 359, 270-272.

Do, Y., et al., 2015. Using internet search behavior to assess public awareness of protected wetlands. Conserv. Biol. 29, 271-279.

Galaz, V., et al., 2010. Can web crawlers revolutionize ecological monitoring? Front. Ecol. Environ. 8, 99-104.

Garibaldi, L.A., et al., 2017. Farming approaches for greater biodiversity, livelihoods, and food security. Trends Ecol. Evol. 32, 68-80.

Graham, M., De Sabbata, S., Zook, M.A., 2015. Towards a study of information geographies:(im) mutable augmentations and a mapping of the geographies of information. GEO: Geogr. Environ. 2, 88-105.

Hallmann, C.A., et al., 2017. More than 75 percent decline over 27 years in total flying insect biomass in protected areas. PLoS One 12 (p. e0185809).

Heimpel, G.E., Mills, N.J., 2017. Biological Control: Ecology and Applications. Cambridge University Press, Cambridge.

Hogue, C.L., 1987. Cultural entomology. Annu. Rev. Entomol. 32, 181-199.

Holland, J.M., et al., 2014. Utilization of agri-environment scheme habitats to enhance invertebrate ecosystem service providers. Agric. Ecosyst. Environ. 183, 103-109.

Hosaka, T., Sugimoto, K., Numata, S., 2017. Childhood experience of nature influences the willingness to coexist with biodiversity in cities. Palgrave Commun. 3, 17071.

Kellert, S.R., 1993. Values and perceptions of invertebrates. Conserv. Biol. 7, 845-855.

Kim, J.Y., et al., 2014. Use of large web-based data to identify public interest and trends related to endangered species. Biodivers. Conserv. 23, 2961-2984.

LaCanne, C.E., Lundgren, J.G., 2018. Regenerative agriculture: merging farming and natural resource conservation profitably. PeerJ 6, e4428.

Ladle, R.J., et al., 2016. Conservation culturomics. Front. Ecol. Environ. 14, 269-275.

Lemelin, R.H., et al., 2016. Humans, insects and their interaction: a multi-faceted analysis. Anim. Stud. J. 5, 65-79.

Losey, J., Vaughan, M., 2006. The economic value of ecological services provided by insects. Bioscience 56, 311-323.

Lundgren, J.G., Fausti, S.W., 2015. Trading biodiversity for pest problems. Sci. Adv. 1 (p. e1500558).

McCallum, M.L., Bury, G.W., 2013. Google search patterns suggest declining interest in the environment. Biodivers. Conserv. 22, 1355-1367.

Michel, J.B., et al., 2011. Quantitative analysis of culture using millions of digitized books. Science 331, 176-182.
Naranjo, S.E., Ellsworth, P.C., Frisvold, G.B., 2015. Economic value of biological control in integrated pest management of managed plant systems. Annu. Rev. Entomol. 60, 621-645.

Nemesio, A., Seixas, D.P., Vasconcelos, H.L., 2013. The public perception of animal diversity: what do postage stamps tell us? Front. Ecol. Environ. 11, 9-10.

NetMarketShare, 2018. https://netmarketshare.com, Accessed date: 17 July 2018.

Pretty, J., Bharucha, Z.P., 2014. Sustainable intensifcation in agricultural systems. Ann. Bot.-London 114, 1571-1596.

Pretty, J., et al., 2018. Global assessment of agricultural system redesign for sustainable intensification. Nature Sustain. 1 (8), 441-446.

Price, P.W., 1988. An overview of organismal interactions in ecosystems in evolutionary and ecological time. Agric. Ecosyst. Environ. 24, 369-377.

Proulx, R., Massicotte, P., Pepino, M., 2014. Googling trends in conservation biology Conserv. Biol. 28, 44-51.

Reganold, J.P., Wachter, J.M., 2016. Organic agriculture in the twenty-first century. Nat. Plants 2, 15221.

Sangha, K.K., et al., 2018. An ecosystem services framework to evaluate indigenous and local peoples' connections with nature. Ecosyst. Serv. 31, 111-125.

Scholes, R., et al., 2018. Summary for Policymakers of the Assessment Report on Land Degradation and Restoration of the Intergovernmental Science-Policy Platform on Biodiversity and Ecosystem Services. IPBES Secretariat, Bonn, Germany (44 pp.).

Schönfelder, M.L., Bogner, F.X., 2017. Individual perception of bees: between perceived danger and willingness to protect. PLoS One 12 (p.e0180168).

Schuetz, J., et al., 2015. Searching for backyard birds in virtual worlds; internet queries mirror real species distributions. Biodivers. Conserv. 24, 1147-1154.

Sherren, K., et al., 2017. Digital archives, big data and image-based culturomics for social impact assessment: opportunities and challenges. Environ. Impact Assess. Rev. 67, 23-30.

Shipley, N.J., Bixler, R.D., 2017. Beautiful bugs, bothersome bugs, and FUN bugs: examining human interactions with insects and other arthropods. Anthrozoös 30, 357-372.

Sitas, N., Baillie, J., Isaac, N., 2009. What are we saving? Developing a standardized approach for conservation action. Anim. Conserv. 12, 231-237.

Sivinski, J., 2013. Augmentative biological control: research and methods to help make it work. CAB Rev. 8, 026 (11 pp).

Southwick, E.E., Southwick Jr., L., 1992. Estimating the economic value of honey bees (Hymenoptera: Apidae) as agricultural pollinators in the United States. J. Econ. Entomol. $85,621-633$.

Stergiou, K.I., 2017. The most famous fish: human relationships with fish as inferred from the corpus of online English books (1800-2000). Ethics Sci. Environ. Pol. 17, 9-18.

Tomasetto, F., et al., 2017. Intensified agriculture favors evolved resistance to biological control. P. Natl. A. Sci. USA 114, 3885-3890.

Tscharntke, T., et al., 2012. Global food security, biodiversity conservation and the future of agricultural intensification. Biol. Conserv. 151, 53-59.

van Lenteren, J.C., 2012. The state of commercial augmentative biological control: plenty of natural enemies, but a frustrating lack of uptake. BioControl 57, 1-20.

van Lenteren, J.C., Bueno, V.H., 2003. Augmentative biological control of arthropods in Latin America. BioControl 48, 23-139.

van Lenteren, J.C., et al., 2018. Biological control using invertebrates and microorganisms: plenty of new opportunities. BioControl 63, 39-59.

Verisign, 2018. The Domain Name Industry Brief. June 2018. https://www.verisign.com/, Accessed date: 18 July 2018.

Warner, K.D., et al., 2011. The decline of public interest agricultural science and the dubious future of crop biological control in California. Agric. Hum. Values 28, 483-496.

Waterfield, G., Zilberman, D., 2012. Pest management in food systems: an economic perspective. Annu. Rev. Environ. Resour. 37, 223-245.

Willer, H., Lernoud, J., 2016. The World of Organic Agriculture. Statistics and Emerging Trends 2016 (pp. 1-336). Research Institute of Organic Agriculture FiBL and IFOAM Organics International.

Wyckhuys, K.A.G., O'Neil, R.J., 2007. Local agro-ecological knowledge and its relationship to farmers' pest management decision making in rural Honduras. Agric. Hum. Values 24, 307-321.

Wyckhuys, K.A.G., et al., 2018. Maximizing farm-level uptake and diffusion of biologica control innovations in today's digital era. BioControl 63, 133-148.

Żmihorski, M., et al., 2013. Ecological correlates of the popularity of birds and butterflies in Internet information resources. Oikos 122, 183-190. 